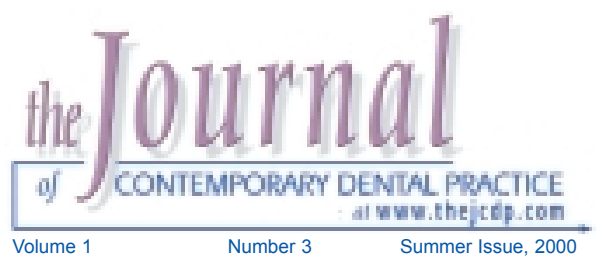

\title{
Oral and Perioral Piercing: A Unique Form of Self-Expression
}

\section{Troye Peticolas, RDH, BS; Terri S.I. Tilliss, RDH, MS, MA; Gail N. Cross-Poline, RDH, MS, MA}

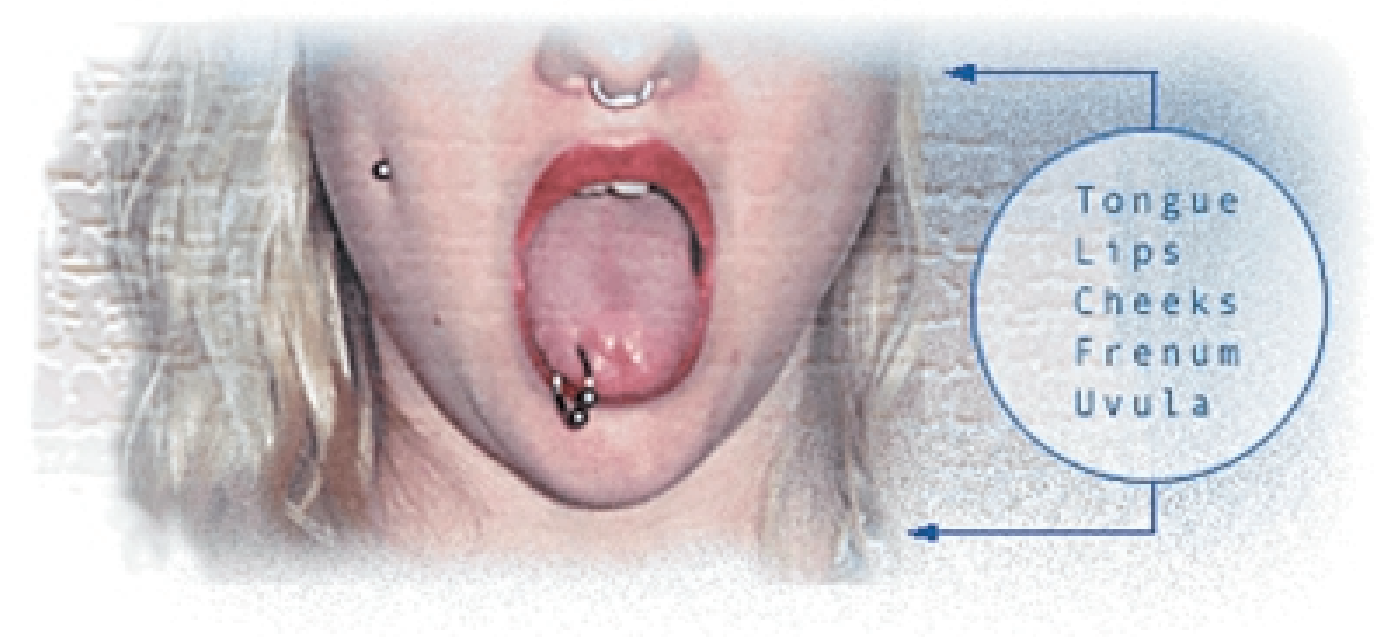

\section{Abstract}

A comprehensive review of oral and perioral piercing is presented. This contemporary phenomenon has many implications for the piercee and for the oral healthcare professional. Oral and perioral piercing, which has become prevalent recently, has historical antecedents. The implications of piercing are described in detail including sites at the tongue, lips, cheeks, frenum, and uvula. Complications occurring immediately after, soon after, and long after the piercing are detailed with special emphasis on the possible deleterious effects on hard and soft oral tissues. Suggestions are provided for patient education including a pamphlet for downloading. Appropriate jewelry selection is described accompanied with a video clip demonstrating removal of jewelry during the dental appointment and a suggested technique for keeping the piercing hole patent while the jewelry is out. Reviewing this information should educate and prepare the oral healthcare professional for the patient presenting with an oral or perioral piercing.

Keywords: Oral piercing, perioral piercing, labrette, piercing, jewelry 


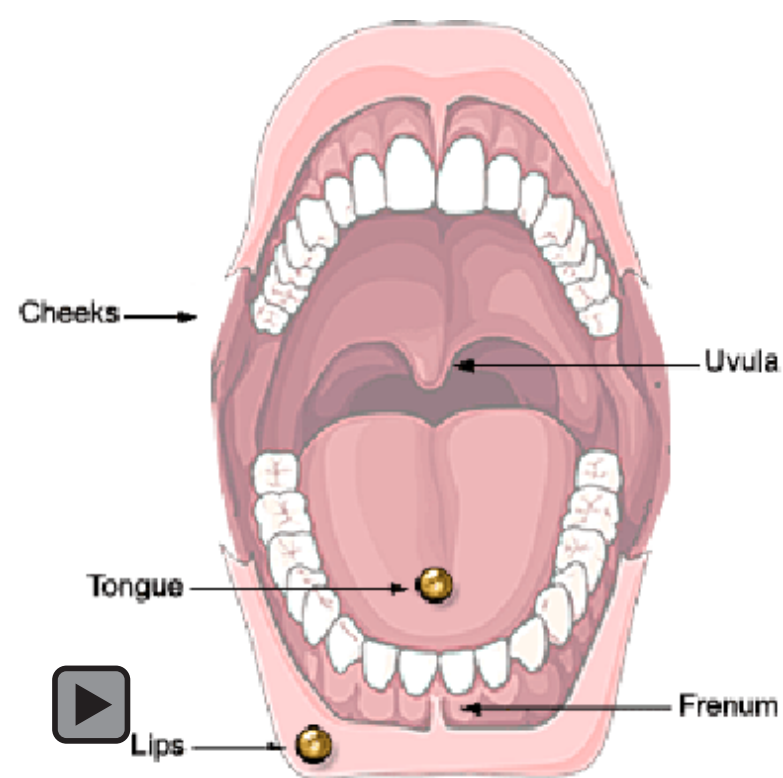

Introduction

Piercing of the tongue and perioral regions have become an increasingly popular form of body art. Tattooing is another common type of body adornment, but the less permanent nature of piercing has more appeal to today's individuals seeking to make personal statements. Oral and perioral piercing has become so prevalent that it is highly likely it is currently or soon will be seen in most dental settings. Therefore, it is imperative oral healthcare professionals are familiar with the phenomenon of oral piercing and well aware of the possible sequelae. Oral/perioral piercing sites for jewelry placement include the (1) tongue, (2) lips, (3) cheeks, (4) frenum, and (5) uvula. ${ }^{1}$ In fact, the American Dental Association has formulated a position statement opposing oral piercing. ${ }^{2}$

\section{Global Significance}

Historically, the Mayans pierced the tongue to demonstrate virility and courage. The Eskimos and Aleuts pierced the lips of female infants as part of a purification ritual and the lower lip of the boys as part of the passage into puberty. The materials used were stones, bones, or ivory. Overall, there has been a decrease in many of these cultural practices with the introduction of Christian influences. ${ }^{3}$

Still today, in some Third World areas, for reasons of "religious, sexual, tribal or marital significance" oral piercings utilizing ivory, wood, pottery, or metal in the mouth are customs that continue to be practiced. ${ }^{4}$ As an example, the Surma tribe of Ethiopia wear large plates on their lower lips. ${ }^{5}$ The married men and widowers of the Suya tribe of Brazil adorn the lower lip with painted wood disks. ${ }^{6}$ The parallels to current day piercing practices are readily apparent (Fig. 1). Other tribes wear plugs on the upper lip or rings in the lower lip. Some peoples in Southern India pierce the tongue with a skewer to maintain a vow of silence. Ritualistic piercings can be temporary and may last only hours. ${ }^{3}$

In the current Western culture, the decision to pierce is often a personal statement representing fashion, risk, and daring. There usually is no formal religious, tribal, or ornamental purpose. However, some piercings such as tongue, genital, and nipple sites, are used for the purpose of increased sexual stimulation.

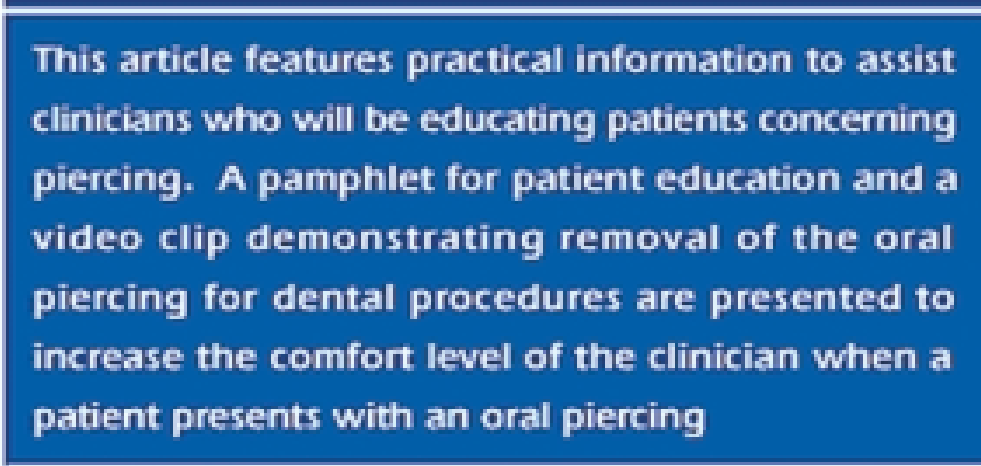

2

The Journal of Contemporary Dental Practice, Volume 1, No. 3, Summer Issue, 2000 


\section{Types of Oral Piercings}

There are several types of oral piercings, however, piercing the tongue is the most common practice. There are two types of tongue piercing; the more common and safer dorsoventral and the dorsolateral. In dorsoventral piercing the jewelry is inserted from the dorsal to the ventral surfaces of the tongue (Fig. 2). This piercing is commonly located in the middle of the tongue and major blood vessels must be avoided during the procedure. Some individuals may choose to have multiple dorsoventral piercings (Fig. 3).

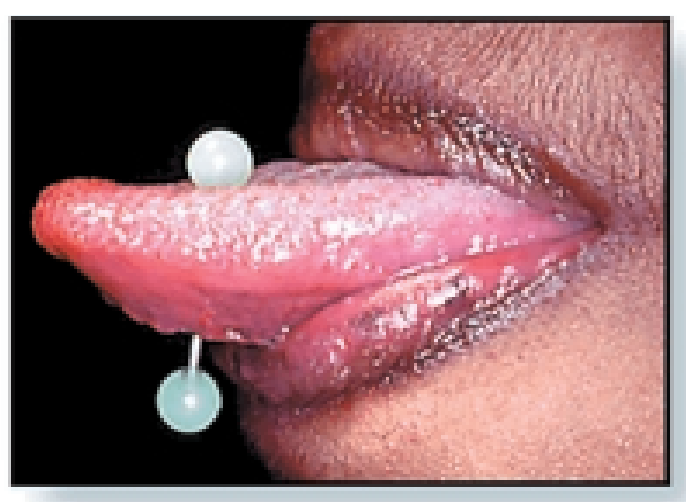

Figure 2: Dorsoventral placement of barbell in tongue

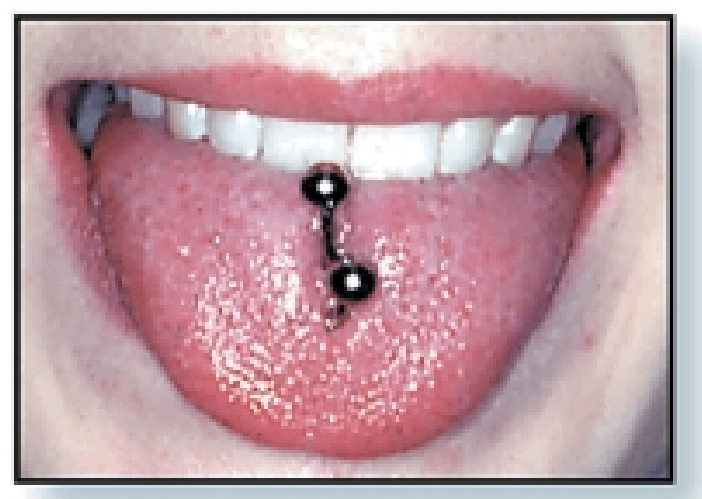

Figure 3: Multiple dorsoventral piercings

Barbells are the most popular form of jewelry placed in the dorsoventral piercing. Tongue rings can also be utilized as jewelry for the tongue when the piercing site is located near the tip or lateral borders of the tongue (Fig. 4).

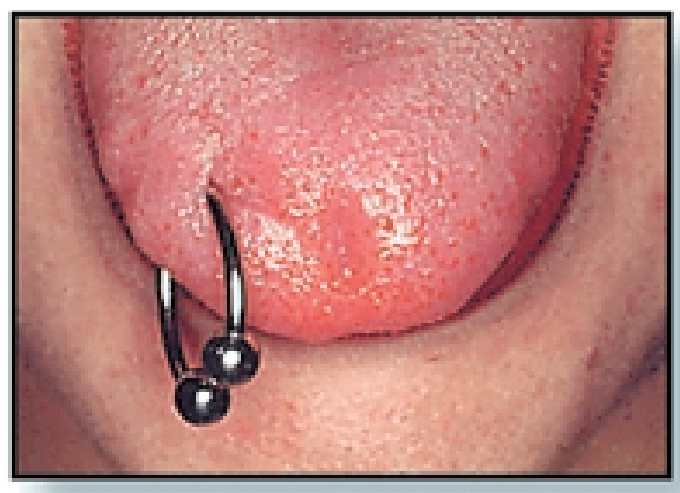

Figure 4: Ring in tongue

The dorsolateral piercing is not a safe procedure due to the vascularity of the tongue; therefore, dorsolateral piercing is not usually performed by professional piercers. In the dorsolateral piercing, both spheres of the jewelry are on the dorsum of the tongue at the lateral borders and located about halfway in an anteroposterior direction. The barbell is placed dorsally, curves down toward the ventral side of the tongue, and resurfaces at the dorsal aspect.

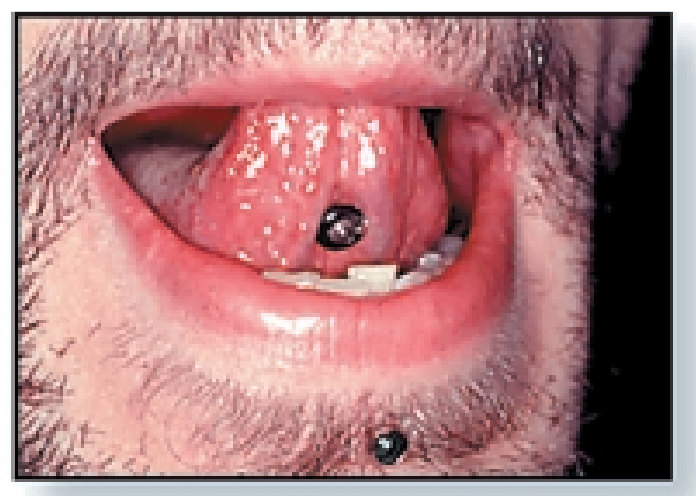

Figure 5: Labrette

Another popular oral piercing is the labrette which refers to piercing sites of the lip. (Fig. 5) One type is placed above the labiomental groove and centered underneath the vermillion border. This piercing site is reminiscent of the lip piercing of the Suya tribe of Brazil and peoples of Africa. ${ }^{4,6}$ The jewelry at this location can contribute to gingival recession at the anterior facial surface of the mandibular region, due to physical trauma to the tissues. 


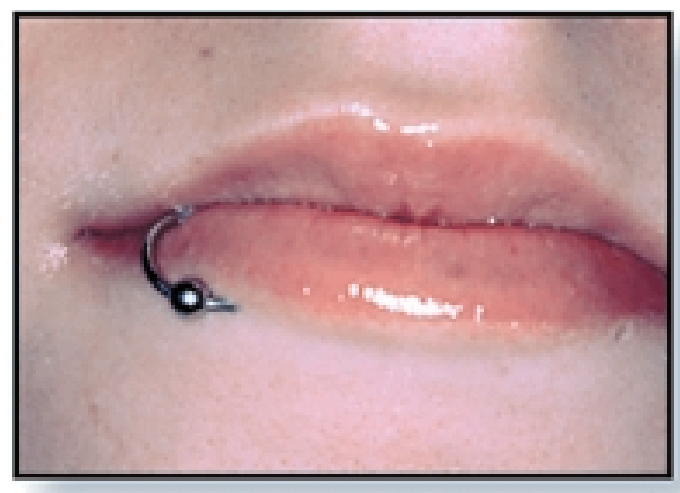

Figure 6: Ring in lip

Lip piercings can be placed anywhere around the vermilion border. The most common site is the side of the lower lip near the commissure. The piercing goes through the lip extraorally and inserts into the oral cavity. A ring often is worn encircling the edge of the lip (Fig. 6).

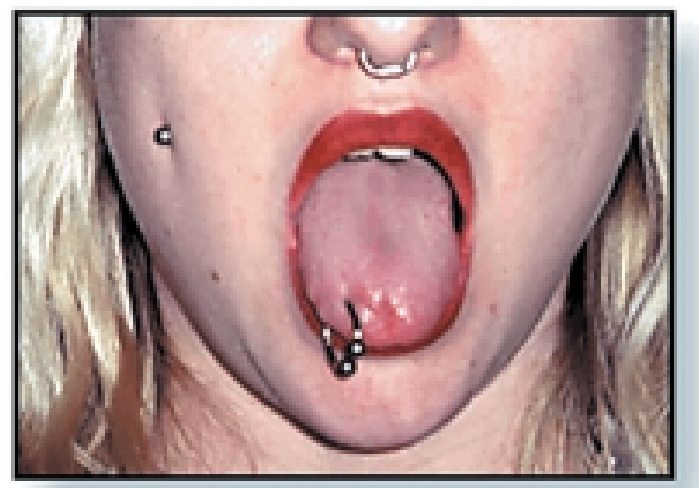

Figure 7: Piercing of the cheek

Other less common oral/perioral piercing locations are the cheeks, lingual frenum, and the uvula. Cheek piercings are known as 'dimples' since the bilateral placement corresponds to usual locations of dimples (Fig. 7). The intraoral placement of the ball of the jewelry at the buccal mucosa can lead to gingival recession and/or abrasion or chipping of the dentition. The lingual frenum location can be referred to as a 'web' piercing. The uvula is not a common piercing site because there are inherent difficulties in performing the piercing and placing the jewelry. Functional issues involving the gag reflex, throat irritation, and deglutition cannot be overlooked. For individuals with several oral piercings the effects on speech, mastication, and deglutition are compounded.

\section{Complications}

Complications resulting from an oral piercing can occur not only during the initial procedure, but at anytime thereafter. It is important for oral healthcare professionals to be aware of these sequelae in order to inform both potential and current piercees and so that complications can be recognized during the oral examination. These effects can happen during the piercing, shortly after, or long after the piercing procedure. . $, 8,9,10,11,12^{2}$

\section{Complications During Piercing}

\section{Hemorrhage}

The highly vascularized tongue, served by the deep lingual artery and vein, will bleed during the procedure. This bleeding should soon be well controlled. Extreme hemorrhaging can occur and should receive immediate attention.

\section{Nerve Damage}

Being highly innervated by the Trigeminal (mandibular division), Facial, Hypoglossal and Glossopharyngeal nerves, it is possible to puncture a nerve during the procedure. This is more common with the dorsolateral than the dorsoventral tongue piercing, but can happen with either. If nerve damage occurs, there can be sensory (taste) or motor effects depending on the nerves affected.

\section{HIV, Hepatitis, Tetanus, and Other Communicable Diseases}

Any of these conditions can result from improper sterilization/disinfection of equipment or supplies. Universal precautions must be utilized throughout the procedure since blood and bodily fluids are involved in piercings. 


\section{Complications Immediately Following Piercing}

Local Inflammation of the Tongue

A swollen tongue can affect speech, mastication, and deglutition. ${ }^{10}$ The submental and /or submandibular lymph nodes may become enlarged and tender. These effects can last up to three to five weeks. The mouth may be treated with a sea salt (saline) soak or rinse to reduce swelling. Persistent symptoms should receive attention.

\section{Localized Infection}

Infection can largely be prevented with meticulous aftercare. Should infection occur, chlorhexidine rinses or systemic antibiotics, and local debridement can hasten healing. Any infection which does not respond in 1-2 days should receive professional attention since such infections can quickly become life threatening.

\section{Trauma to Lingual Gingiva}

Erythema and edema of the gingiva is caused by the tendency to 'play' with the tongue ball by rubbing it against lingual gingiva. This can occur from placement of the dorsal ball against the maxillary lingual tissue or the ventral ball against the mandibular lingual tissues.

\section{Bacteremia}

A systemic infection can result from bacteria introduced during piercing or can spread from a localized infection that can occur anytime. A healthcare provider should be consulted if symptoms occur such as fever, chills, shaking, or a red streaked appearance near the piercing site.

\section{Ludwig's Angina}

This condition involves an inflammation of connective tissue. It spreads rapidly to involve submandibular, submental, and sublingual spaces. Signs would be painful tongue swelling, difficulty swallowing and speaking, and compromised airway. This is a serious development that demands immediate professional intervention. A compromised airway could prove fatal. ${ }^{11}$

\section{Long-Term Complications}

\section{Tissue Hyperplasia}

Tissue overgrowth can occur at the site and may be accompanied by pain and edema. The tissue can be excised, the wound treated, irrigated, and then followed with re-insertion of a sterile barbell. The tissues can repeatedly become hyperplastic after excision.

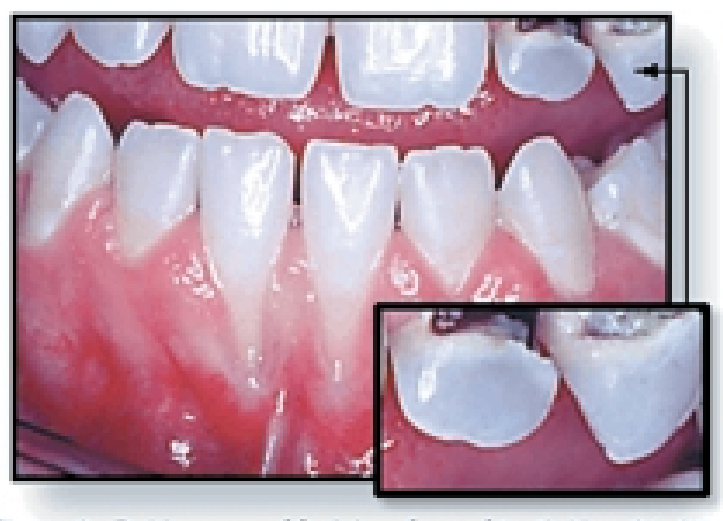

Figure 8: Dehiscence of facial surface of teeth Nos. 24, 25

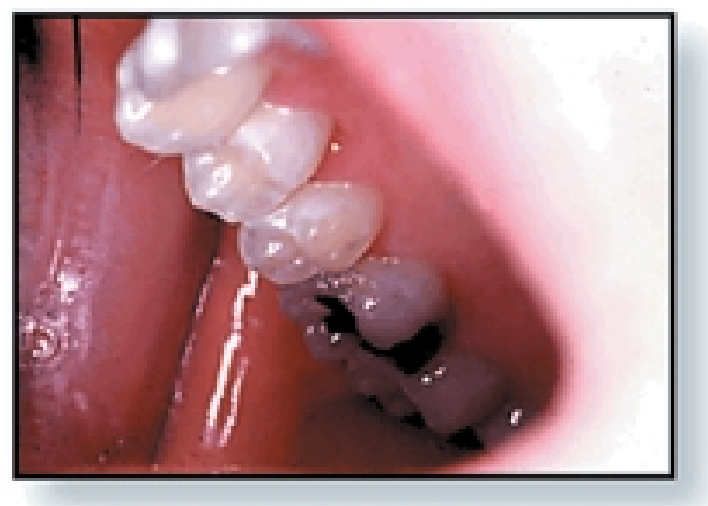

Figure 9: Fractured cusp of tooth No. 13

\section{Dehiscence (Fig. 8)}

The ball of the labrette or lip barbell rubbing against the mandibular anterior facial gingiva can create a dehiscence over time. This could occur at any location where metal continually abrades against soft tissues. A periodontal consultation is advisable if this condition occurs.

\section{Cracked /Fractured Teeth (Fig. 9)}

Damage to teeth can result from parafunctional oral habits related to biting the barbell, careless jewelry insertion, or during eating. Damage to teeth is most likely to occur after swelling has diminished and the barbell fits loosely within the tongue. Maxillary or mandibular teeth can sustain chipping from the ventral or the dorsal ball 
on the tongue..$^{8,9}$ Symptoms include sensitivity to cold and sweets and pain upon biting pressure. The dental clinician who has administered a mandibular block injection should be aware that while the patient is still anesthetized, jewelry in the numbed tongue can readily result in cracked/chipped teeth during loss of tongue control.

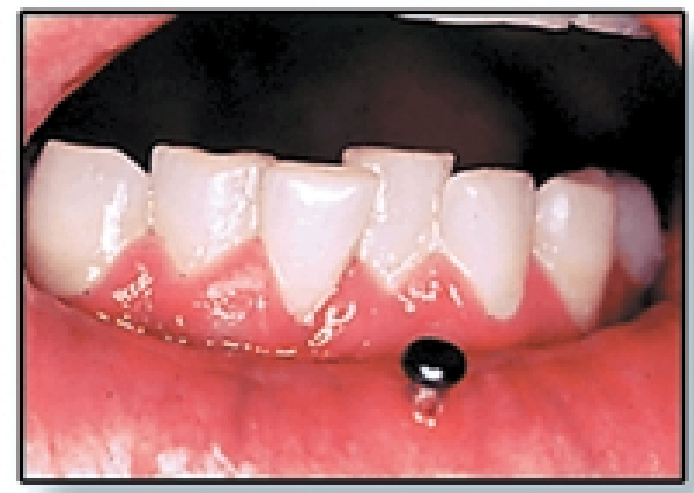

Figure 10: Gingival Recession of facial surface of tooth No. 25

Gingival Recession/Tooth Abrasion (Fig. 10) The tendency to repeatedly press the tongue barbell against the mandibular lingual gingiva can lead to slight, moderate, or severe recession of soft tissues. Labrette or lip piercings can cause recession of the mandibular facial tissue. ${ }^{8}$ Similarly, the dentition can be abraded by the jewelry. Cosmetic or functional correction can be implemented by a dentist.

\section{Aspiration or Ingestion}

A metal bar connects two balls of the barbell. One side of the rod has threads for screwing the ball into position; this side is placed on the dorsum. If the ball becomes loosened, there is a potential for swallowing or aspirating it.

Additionally, during removal or reinsertion, the ball could inadvertently slip down the throat.

Aspiration or inhalation of jewelry parts could occur at anytime after a piercing.

\section{Selection of Jewelry}

An important aspect of body piercing is selecting proper jewelry, which is usually sold at the piercing studio. This jewelry should be made of inert non-toxic metal substances such as $14 \mathrm{k}$ or $18 \mathrm{k}$ gold, surgical stainless steel, titanium, or niobium. While the body piercing procedure may cost from
$\$ 15$ to $\$ 50$, the purchase of body jewelry is an additional cost that can range from $\$ 35$ to $\$ 100$. Some individuals do not anticipate the cost of jewelry when considering a piercing. Since proper jewelry for the procedure may be seen as a frivolous extra cost, the adolescent may decide to place costume jewelry or a safety pin in the opening instead. However, there is no substitute for quality jewelry, since silver plating and finishes on costume jewelry wear off quickly, leaving abrasive brass that predisposes the pierced sites to infections and allergic responses.

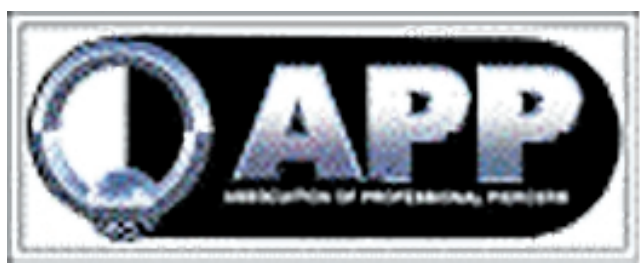

\section{Patient Education}

It is important for oral healthcare professionals to inform and educate prospective and new piercees. This includes advising on safety and health issues as well as obtaining and maintaining optimal oral hygiene during and after the procedure. An excellent brochure for patients has been produced by the Association of Professional Piercers and a copy can be downloaded from the Association's web site at:

http://www.safepiercing.com/

If a patient or a concerned parent requests advice about tongue piercing, these points should be emphasized:

- Need for maturity/responsibility of the piercee since there is 'upkeep' with the piercing site.

- Careful evaluation of the piercing establishment focusing upon sterilization and infection control as well as issues and credentials of the piercer.

- During the initial 3-4 week healing period the tongue is swollen which affects speaking and eating.

- The possibility of infection always exists, as well as fractured teeth and gum recession, which may require professional intervention.

- Quality jewelry of the appropriate size is a must. 


\section{Management of the Dental Patient}

Usually a patient presenting with an oral piercing will not require any special considerations by the oral healthcare professional during treatment. However, when jewelry removal is indicated a well-prepared dental team should have the necessary supplies available in the office. This is important because when oral piercing jewelry is removed, closure may begin to occur in a short time.

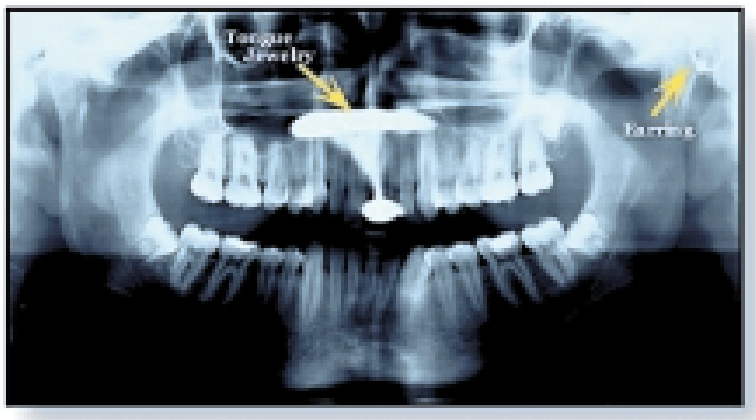

Panoramic radiograph of a patient with tongue jewelry pressed against the maxillary anterior teeth and a pierced earring in the left ear.

During exposure of radiographs, it is often necessary to remove jewelry. For panoramic radiographs, all jewelry should be removed above the neck. Cheek and labrette jewelry should be removed for periapicals and bitewing radiographs because of their location in relation to film placement and tube head.

The need for jewelry removal during local anesthesia is at the discretion of the oral healthcare professional. The mandibular block is one injection for which jewelry removal may be prudent. When the tongue is anesthetized, there is increased possibility for tooth damage until the anesthesia has completely disappeared.

A well-prepared office will have temporary nonmetal replacements for oral jewelry that is removed for treatment. Hole closure is highly variable among individuals and in case the patient is not prepared, it is recommended that the oral healthcare professional provide a replacement to keep the piercing site patent.
One simple and inexpensive method is to provide nylon line used in lawn care equipment, such as a weed eater, as a suitable choice for a non-metal replacement. This material is available in different diameters. The equivalent of 12-14 gauge for tongue piercings and 14 gauge for other oral piercings is comparable in size to the jewelry normally used. The following steps can be used to prepare the line

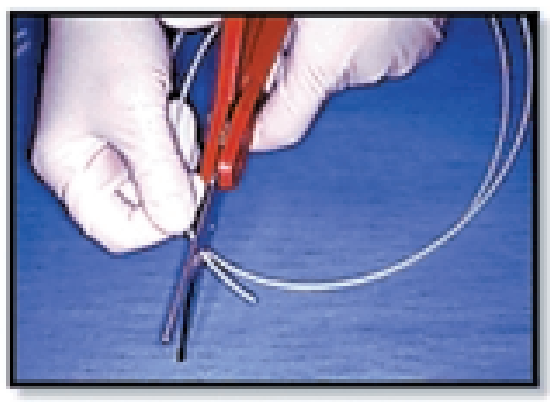

Figure 11: Cutting nylon line

Cut the line to $11 / 2$ " lengths (Fig. 11)

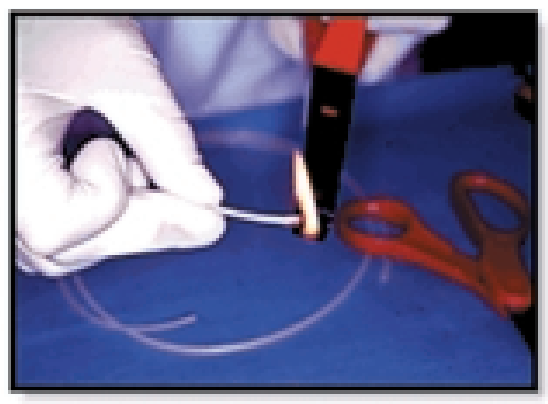

Figure 12: Melting one end of nylon line

Melt one end by fire, i.e., lighter or match (Fig. 12)

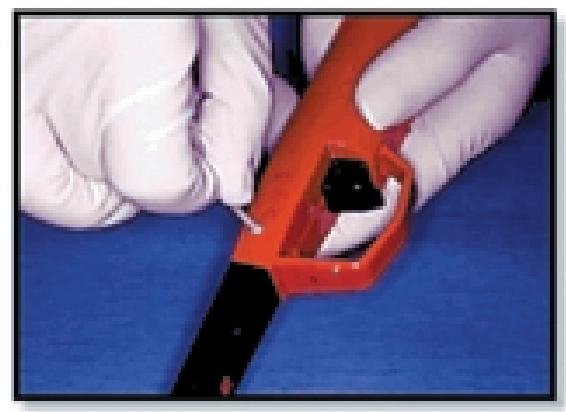

Figure 13: Creating the "stop" end

While warm, gently press this end against a flat surface. The resulting end will be widened and flattened and serve as a 'stop'. (Fig. 13) 


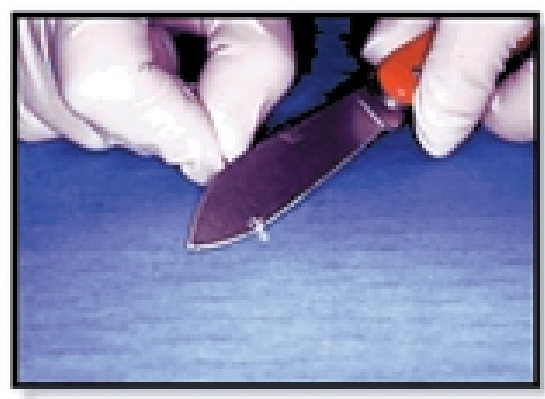

Figure 14: Smoothing the rough end

With a pocketknife or scaler, smooth the rough end of the other side, narrowing the edge for more comfortable insertion. (Fig. 14)

Package separately and autoclave individually.

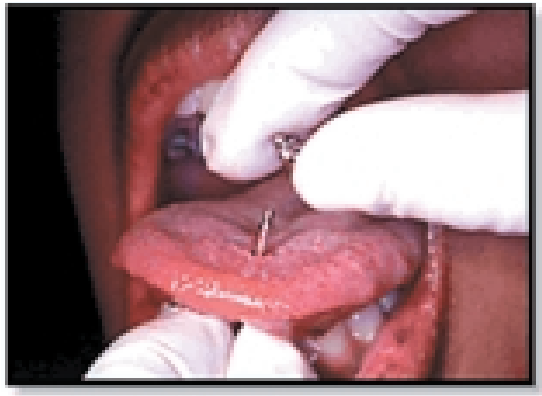

Figure 15: Unscrewing

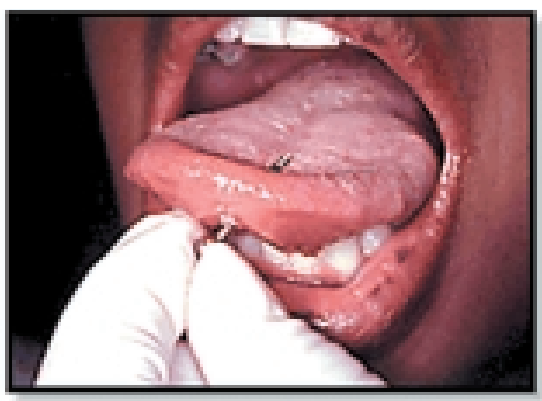

Figure 16: Removing tongue jewelry

The patient or the clinician should unscrew and remove the jewelry (Fig. 15, 16).

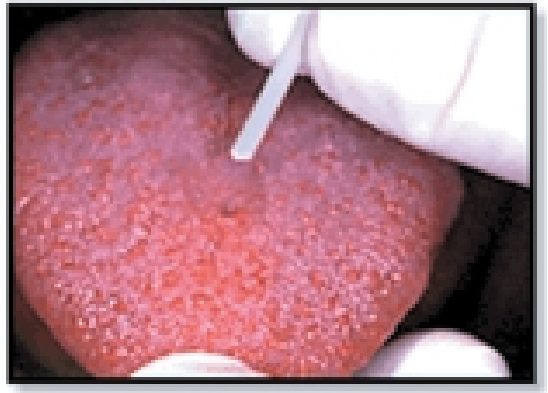

Figure 17: Insertion of nylon line

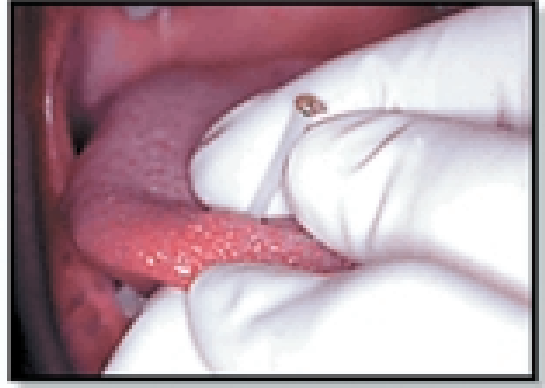

Figure 18: Insertion of nylon line

Quickly insert the nylon line (Fig. 17, 18).

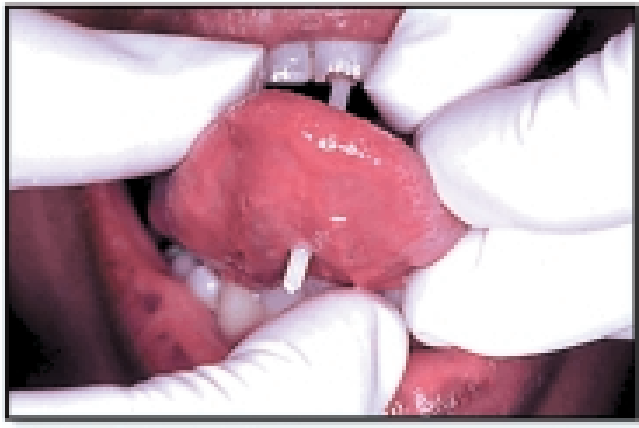

Figure 19: "Stop" end at dorsum

For the tongue piercing, the flattened end of the line 'stop' would rest on the dorsum of the tongue (Fig. 19).

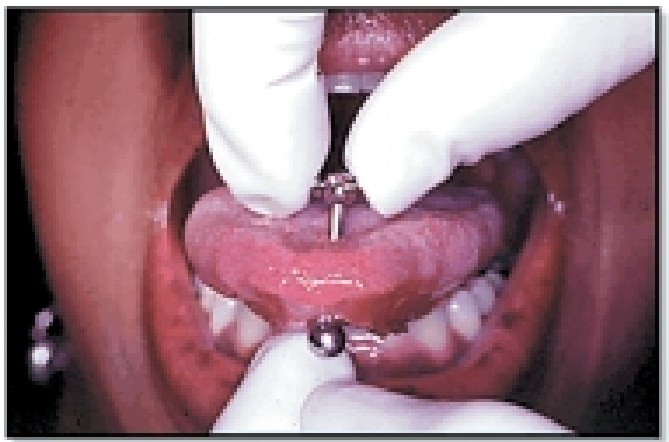

Figure 20: Re-insertion of jewelry

For the cheek, labrette, or lip piercings, insert the line from the mucosal side, leaving the flattened end intraorally. After the dental procedure, the nylon line is removed and the jewelry re-inserted into the piercing site (Fig. 20). 


\section{Conclusion}

Today's oral healthcare professionals are likely to see patients with, or considering oral/perioral

piercing sites. Educating and advising these perspective or current piercees about the oral and systemic ramifications of this practice can be a helpful service. When jewelry removal is indicat- ed prior to a dental procedure, it is important for the oral healthcare professional to be familiar with this process. Staying current with societal trends that affect the oral cavity will contribute toward comprehensive care for those served.

\section{References}

1. Armstrong ML. You pierced what? Pediatr Nurs 1996;22(3): 236-238.

2. American Dental Association, Current Policies, Prevention and Health Education, Policy Statement on Intraoral/perioral Piercing, Chicago, American Dental Association, 1998:743.

3. Ring ME. Dentistry: An illustrated history. Harry N. Abrams, Inc., ed. New York;1984.

4. Fisher A. Africa adorned. W. Collins, ed. London; 1984.

5. Beckwith C, Fisher A. The eloquent Surma of Ethiopia. National Geographic Magazine 1991;179(2): 77-91.

6. Schultz H. Brazil's big-lipped Indians. National Geographic Magazine 1962;121(1): 119-125.

7. Price SS, Lewis MW. Body piercing involving oral sites. J Am Dent Assoc 1997;128(7): 1017-1020.

8. Boardman R, Smith RA. Dental implications of oral piercing. CDA J 1997;25(3): 201-207.

9. Diangelis AJ. The lingual barbell: A new etiology for the cracked-tooth syndrome. J Am Dent Assoc 1997;128: 1438-1439.

10. Fehrenbach MJ. Tongue piercing and potential oral complications. J Den Hyg 1998;72(1): 23-25.

11. Perkins CS, Meisner J, Harrison JM. A complication of tongue piercing. Br Dent J 1997;182(4): 147-148.

12. Maibaum WW, Margherita VA. Tongue piercing: a concern for the dentist. Gen Dent 1997 SepOct;45(5): 495-497. 


\section{About the Authors}

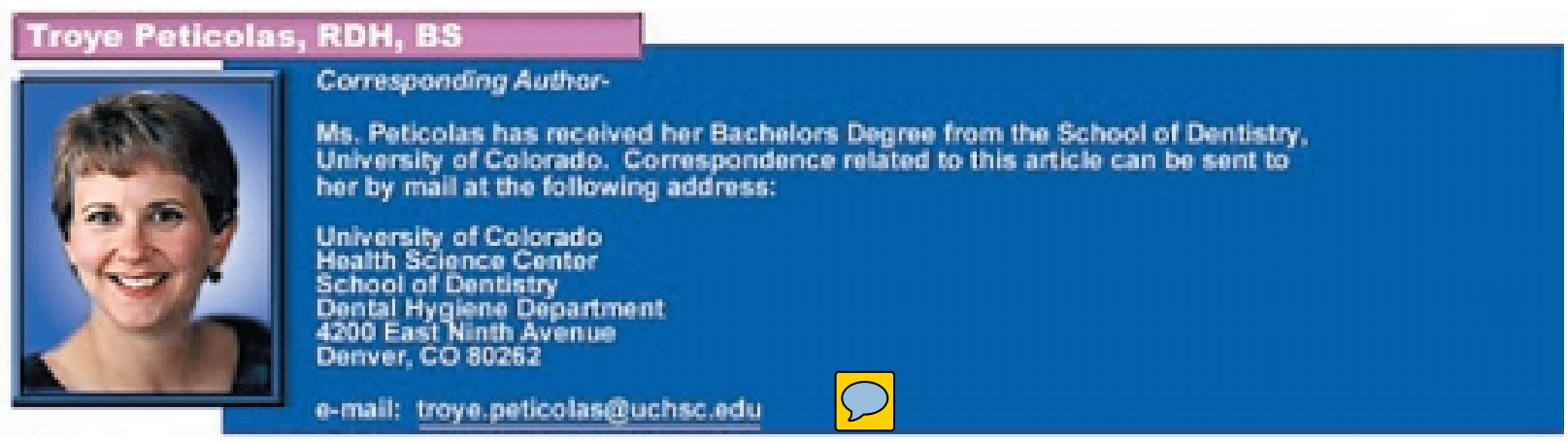

\section{Torri S.I. TIIIIss, RDH, MS, MA}

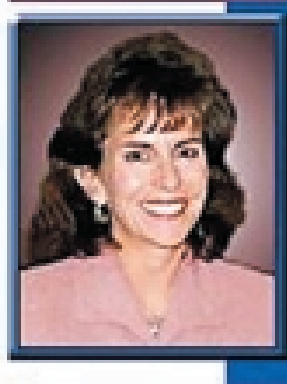

Ns. Tilliss is an Associate Professer in the Department of Dental Hygiene at the

School of Dentistry, University of Colarado. Correspondence related to this article can be sent to her by mail at the following address:

University of Colorado

Health Science Center

School of Dentistry

Dental Hygiene Department

4200 East Winth Avenue C284

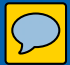

Denver, Co 80262

0-mail: terri.tilliss@uchsc.odu

\section{Gall N. Cross-Poline, RDH, MS}

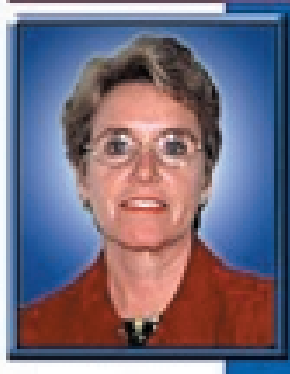

Ms. Cross-Poline is Chair and Associate Prolessor in the Department of Dental Hygiene at the School of Dentistry, University of Colorado. Correspondence related to this article can be sent to her by mail at the following address:

Uniwersity of Colorado

Hoalth Scionces Conter

School of Dentistry

Dental Hygiene Department

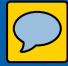

4200 East Ninth Avenue

Denver, CO 80262

o-mali: gailicross-polineguchsc.edu

\section{Acknowledgements}

The authors are grateful for the contribution of photographs made by John McDowell, DDS, MS, and by Norman Stoller, DMD, at the University of Colorado Health Sciences Center School of Dentistry and to Ms. Julianne Gerbig for her initial involvement with this project. 